\title{
Crystal Population Growth in a Continuous Helically Coiled Flow Tube Crystallizer
}

\author{
Viktoria Wiedmeyer ${ }^{1, *}$ \\ Dr. Andreas Voigt ${ }^{1}$ \\ Prof. Kai Sundmacher ${ }^{1,2}$
}

${ }^{1}$ Otto von Guericke University Magdeburg, Department Process Systems Engineering, Universitätsplatz 2, 39106 Magdeburg, Germany

${ }^{2}$ Max Planck Institute for Dynamics of Complex Technical Systems, Process Systems Engineering, Sandtorstr.1, 39106 Magdeburg, Germany

\section{${ }^{*}$ Corresponding author}

Email: viktoria.wiedmeyer@ovgu.de

\begin{abstract}
A helically coiled flow tube crystallizer was investigated as a novel device for the shapeselective generation of crystals with potassium alum as the model solid. The shape evolution of the crystal population was analyzed for growth-dominated seeded cooling crystallization. The macro-mixing behavior was characterized by residence time distribution measurements for the fluid phase and the crystals. At the crystallizer outlet, a flow-through microscope was used to analyze the crystal size and shape distribution, where the 3D shape of individual crystals was estimated from 2D projections. The experiments showed a separation of the particle population according to the crystal size. This process allows the controlled shaping of crystals under continuous operating conditions.
\end{abstract}

\section{Keywords}

Crystal shape, Crystallization, Helically coiled tube, Particle Size, Residence time distribution

\section{Introduction}

The shape of a crystal strongly influences its bioavailability, filterability, and flowability. For many applications where these parameters are important, it is therefore desirable to achieve a narrow crystal shape distribution. Continuous crystallization has the advantage of reduced breakage caused by stirring and avoids batch-to-batch variability, although tubular crystallizers may be affected by blocking. Typical continuous tubular setups include straight tubes as presented by Borchert and Sundmacher for crystal aggregation [1], helically coiled 
flow tubes (HCTs) as studied with respect to flow profiles by Vashisth and Nigam [2], and coiled flow inverters (CFIs) as applied for crystallization by Hohmann et al. [3]. The mixing properties of the previously mentioned tubular crystallizers increase from straight tubes to CFIs as shown by Klutz et al. [4]. Here, a HCT crystallizer was chosen as a novel device because of its compactness, flexible geometry, high heat exchange rates, and narrow residence time distribution (RTD). Coiled tubular crystallizers have been applied for crystal size control of active pharmaceutical ingredients by Khinast and co-workers [5-8]. The aim of this paper was to determine whether continuous shape-selective crystallization is possible in a HCT.

The final crystal shape that can be reached in a HCT is determined by the residence time (RT) of the dispersed phase. In HCTs, a complex flow profile with Dean vortices can develop. Consequently, a secondary fluid motion acts on the particles. Vashisth and Nigam investigated the two-phase flow in coiled tubes and surveyed experimental and theoretical studies of HCTs [2]. They characterized the geometry and flow conditions of HCT setups by the following dimensionless numbers: curvature ratio $\lambda$, dimensionless pitch $P$, Reynolds number $R e$, and Dean number $D e$, as defined in Eqs. (1)-(4).

$\lambda=\operatorname{rcr}$

$\mathrm{P}=\mathrm{p} 2 \pi \mathrm{rc}$

$\operatorname{Re}=\operatorname{dv} \rho \mu$

$\mathrm{De}=\operatorname{Re} \lambda$

where $r_{\mathrm{c}}$ is the coil radius, $r$ is the internal tube radius, $d$ is the internal tube diameter, $p$ is the screw pitch, $v$ is the average fluid velocity, $\rho$ is the fluid density, and $\mu$ is the dynamic viscosity of the fluid. Furthermore, Klutz et al. combined $P$ in Eq. (2) and $R e$ in Eq. (3) in the dimensionless torsion parameter $t$ to compare the HCT to a straight tube with regard to RT [4].

$\mathrm{t}=\mathrm{PRe}$

Several inline imaging devices and corresponding imaging methods for shape estimation have been reported in the literature, e.g., the custom-made microscope applied by Schorsch et al. [9]. Here, a commercial microscope was applied, which was also used by Borchert et al. [10]. The crystal shape evolution was investigated experimentally for a univariate model substance, i.e., a crystal shape that can be described by one internal coordinate. The results may serve as a basis for the analysis of bivariate and multivariate crystal populations. Furthermore, the experimental results of this work can be applied to the estimation of growth kinetics. Experimentally validated growth kinetics are required for process design to reach a desired crystal shape distribution. 


\section{Materials and Methods}

The potash alum solution and the seed crystals were prepared from the same starting material, potassium alum sulfate dodecahydrate (Merck, CAS No. 7784-24-9, purity $\geq 99 \%$ ). Seed crystal fractions were prepared by sieving with mesh sizes of 150-200, 200-212, 212300 , and $300-400 \mu \mathrm{m}$. Ultrapure water (LaboStar 2-UV, Evoqua) was used as the solvent.

An aqueous solution of potash alum was pumped using a gear pump (4030-280-DM-25-6, Scherzinger Pump Technology) from a reservoir to the HCT. As shown in Fig. 1, the dispersion leaving the HCT was recorded using a flow-through microscope (QICPIC R02, Sympatec) and then again dissolved in the reservoir.

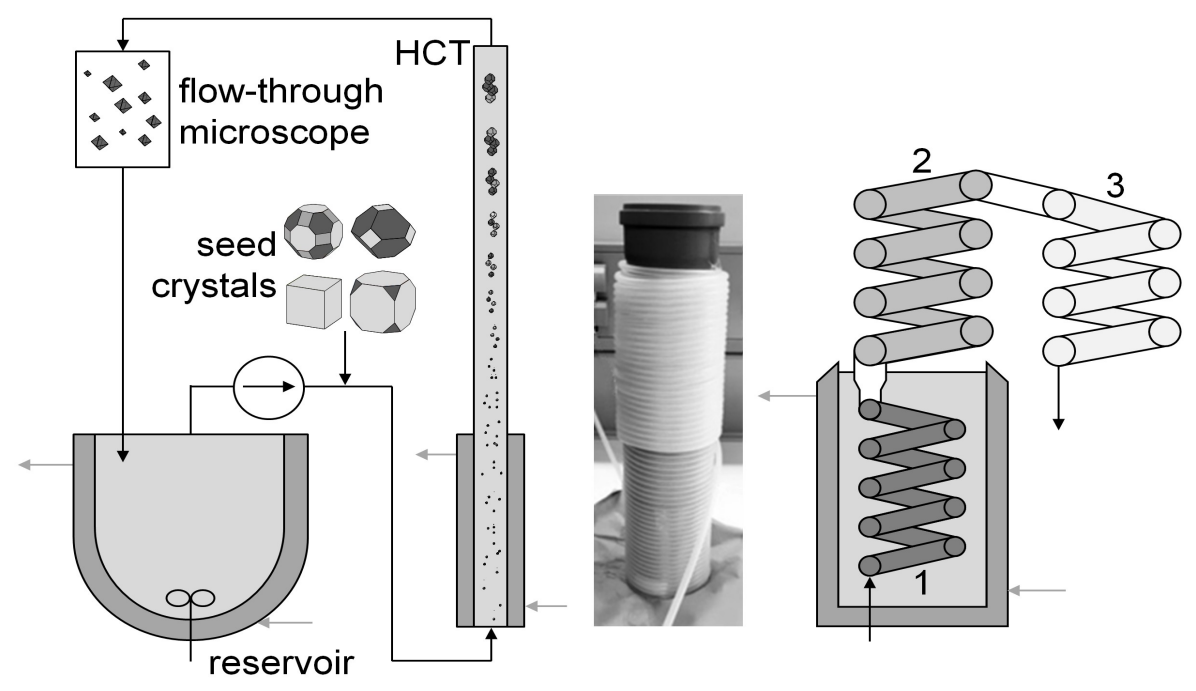

Figure 1. Schematic of the experimental setup with reservoir, pump, helically coiled flow tube crystallizer (HCT), and flow- through microscope, and geometrical details of the HCT. Tube section 1 is dark-gray colored, tube section 2 is gray colored, and tube section 3 is light-gray colored.

The HCT geometry was fixed. As shown in Fig. 1, the HCT used in this study is composed of a coiled-up tube (1) in a cooling bath that is fed from the bottom, an upward coiled tube (2) in air and a downward coiled tube (3) in air. The tubes are made from silicone with wall thickness $w$. Tube sections (1) and (2) are helically coiled upward on a propylene pipe. Tube section (3) is downward coiled on the outside of tube section (2). The dimensions of the HCT sections are shown in Fig. 2 a and Tab. 1, where the screw pitch $p_{\mathrm{i}}$ equals the outer tube diameter for all tube sections $i$. 

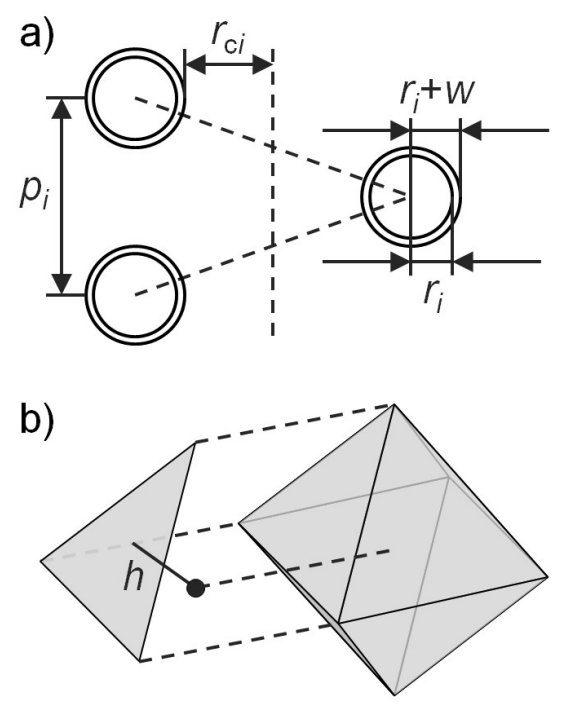

Figure 2. (a) Characteristic dimensions of the sections i of the helically coiled flow tube are shown in a vertical cut plane through the center of the helical tube. (b) Ideal octahedral potash alum crystal with the perpendicular distance $\mathrm{h}$ from the crystal center to the crystal face.

Table 1. Dimensions of the three successive tube sections, which are shown schematically in Fig. 1 and dimensioned in Fig. 2 for each tube section $i$. The tube arc length $/$ is given for the centerline of the tube.

\begin{tabular}{|l|l|l|l|}
\hline & Sect. 1 & Sect. 2 & Sect. 3 \\
\hline$I[\mathrm{~m}]$ & 8 & 13 & 12 \\
\hline$r[\mathrm{~m}]$ & 0.0025 & 0.003 & 0.003 \\
\hline$r_{\mathrm{c}}[\mathrm{m}]$ & 0.055 & 0.055 & 0.059 \\
\hline$w[\mathrm{~m}]$ & 0.0015 & 0.0015 & 0.0015 \\
\hline$p[\mathrm{~m}]$ & 0.008 & 0.009 & 0.009 \\
\hline
\end{tabular}

Characteristic pulsation curves were made available by the pump manufacturer (Scherzinger Pump Technology) for a pump with an identical working principle (4030-450, magnetically coupled gear pump) but with a larger displacement. In measurements with water at $12.5 \mathrm{~Hz}$ and 2 bar, the peak amplitude was 0.4 bar. In measurements at both 2 and 5 bar, the peak amplitude amounted to $20 \%$ of the mean pressure. The pump speed applied in this work accounts for one third of this value. For a lower pump speed, the pulsation increases. Thus, there was considerable pulsation at the operating point of the pump chosen in this work. The pulsation increases axial backmixing.

Microscopy images were used to analyze the crystal RTD and the crystal size and shape distribution (CSSD). The 3D shape of the individual crystals was estimated from 2D microscope projections, as reported by Borchert et al. [10]. The crystal shape was 
characterized by the perpendicular face distance $h$ from the center of each octahedral crystal, as shown in Fig. 2 b. Nuclei and agglomerates were identified by imaging methods and separated from the growth observation.

The RTD of the fluid phase, the RTD of the dispersed phase, and crystal growth were investigated in separate experiments. In all of the experiments, a low and a high pump speed were applied. In preliminary mass-flow measurements, the mass flow of the potassium alum solution at $313 \mathrm{~K}$ was determined as 7.8 and $11.2 \mathrm{~g} \mathrm{~s}^{-1}$ for the selected pump speeds of 3.3 and $5.0 \mathrm{~Hz}$, respectively.

The RT of the continuous phase was analyzed via conductivity measurements. The conductivity probe (FYA641LFP1, Ahlborn) had a small dead zone between the electrodes of $27 \times 10^{-7} \mathrm{~m}^{3}$. In the measurements, the HCT feed was changed from pure water to a brief pulse of potash alum water solution with a conductivity of $1.8 \mathrm{~S} \mathrm{~m}^{-1}$ for a defined duration from 5 to $22 \mathrm{~s}$.

The RTD experiments for the dispersed phase were performed under isothermal conditions, whereas the temperature profiles varied for the growth experiments during cooling crystallization. The inlet and outlet temperatures of the HCT were measured to determine the supersaturation ratio of the solution. Both types of experiment were conducted at steady state with respect to the temperature profile. The inlet concentration was fixed at $243 \mathrm{~g}$ potash alum sulfate dodecahydrate per $\mathrm{kg}$ free water, which corresponds to a saturation temperature of $313 \mathrm{~K}$ [11]. Dry seeding experiments were performed with all sieve fractions separately and for a mixture of the smallest and the largest sieve fractions. For the latter case, the two fractions were mixed prior to seeding. For each isothermal and growth experiment, the sieve fraction size and seed mass are given in Tab. 2. Assuming that the seed crystals were distributed in a section of the seed addition nozzle of $1 \mathrm{~cm}$ in length, the seed volume fraction in this section was 11 to $24 \%$ for the seed crystal masses given in Tab. 2. On the basis of the HCT volume, the seed volume fraction was 0.007 to $0.014 \%$.

Table 2. Sieve fraction and seed mass for the isothermal and growth experiments in Fig. 3 and Fig. 4.

\begin{tabular}{|l|l|l|l|l|l|}
\hline & \multicolumn{5}{|l|}{ Mass of seeds in the sieve fraction $[\mathrm{g}]$} \\
\hline $\begin{array}{l}\text { Experiment } \\
\text { Type }\end{array}$ & $\begin{array}{l}\text { Mass flow rate } \\
{\left[\mathrm{g} \mathrm{s}^{-1}\right]}\end{array}$ & $150-200 \mu \mathrm{m}$ & $200-212 \mu \mathrm{m}$ & $212-300 \mu \mathrm{m}$ & $\begin{array}{l}300-400 \\
\mu \mathrm{m}\end{array}$ \\
\hline Isothermal & 7.8 & 0.116 & - & - & - \\
\hline Isothermal & 7.8 & 0.118 & - & - & - \\
\hline Isothermal & 7.8 & - & 0.105 & - & - \\
\hline Isothermal & 7.8 & - & 0.105 & - & - \\
\hline
\end{tabular}




\begin{tabular}{|l|l|l|l|l|l|}
\hline Isothermal & 7.8 & - & - & 0.128 & - \\
\hline Isothermal & 7.8 & - & - & 0.103 & - \\
\hline Isothermal & 7.8 & - & - & - & 0.113 \\
\hline Isothermal & 7.8 & 0.050 & - & - & 0.153 \\
\hline Isothermal & 7.8 & 0.049 & - & - & 0.166 \\
\hline Isothermal & 11.2 & 0.100 & - & - & - \\
\hline Isothermal & 11.2 & - & 0.102 & - & - \\
\hline Isothermal & 11.2 & - & - & 0.153 & - \\
\hline Isothermal & 11.2 & - & - & - & 0.204 \\
\hline Isothermal & 11.2 & 0.053 & - & - & 0.153 \\
\hline Isothermal & 11.2 & 0.061 & - & - & 0.151 \\
\hline Growth & 7.8 & 0.108 & - & - & - \\
\hline Growth & 7.8 & 0.106 & - & - & - \\
\hline Growth & 7.8 & 0.108 & - & - & - \\
\hline
\end{tabular}

\section{Results and Discussion}

The final crystal shape is influenced by the time a crystal remains in the tube. The growth kinetics depend on the supersaturation of the fluid, i.e., the fluid and crystal RTDs determine the duration of crystal growth. Thus, initially, the fluid RTD was analyzed. For a total internal tube volume of $8.6 \times 10^{-4} \mathrm{~m}^{3}$ and mass flow rates of 7.8 and $11.2 \mathrm{~g} \mathrm{~s}^{-1}$, the average RTs of the continuous phase were 120 and $84 \mathrm{~s}$, respectively. For both mass flow rates, the resulting dimensionless numbers in Eqs. (1)-(5) are listed in Tab. 3. In general, an increase in mass flow leads to an increase in $R e$ and $D e$ and a decrease in $t$. The curvature induces centrifugal forces and consequently secondary flow [12]. For similar dimensionless numbers, RedlingerPohn et al. found that the influence of $\lambda$ on the secondary flow is significantly greater than that of $\operatorname{Re}$ [13]. In our work, $\lambda$ is also in the range of the work of Vashisth and Nigam [2]. The dimensionless pitch $P$ of $0.02-0.03$ is slightly lower in our work compared to the previously reported value of $0.03-0.08$ [2]. These authors stated that with increasing $P$ the fluid velocity contours become more asymmetrical and complex compared to a torus of zero pitch. $R e$ was based on the fluid density at a saturation temperature and an operating temperature of $313 \mathrm{~K}$ according to Kubota et al. [14]. The dynamic fluid viscosity was taken from Mullin et al. [15] at identical temperatures. A high $R e$ improves mixing, whereas a low $R e$ decreases the tube length, which is required to reach a certain RT and thus growth. As shown in Tab. 3, for the lower mass flow rate, $R e$ was between 1788 in the first tube and 1490 in the second and third tube sections, while for the higher mass flow rate it was between 2550 and 2125 . Therefore, it was only in the case of the first tube section at the higher mass flow rate that $R e$ was above the critical Reynolds number $R e_{\text {crit }}$ for straight tubes of 2300 [16]. In the other cases, $R e$ was in the laminar range. Curved tubes have higher $R e_{\text {crit }}$ compared to straight pipes [12]. Vashisth and Kumar explained that the secondary flow stabilizes the laminar fluid flow in coiled tubes and compiled a list of correlations for the $R e_{\text {crit }}$ of turbulence [12]. By 
comparing $R e_{\text {crit }}$ for all tube sections, the correlation of Kubair and Varrier [17] yields the lowest $R e_{\text {crit }}$ of 4734 in the third tube section. Thus, all values of $R e_{\text {crit }}$ in this work were significantly below the lowest $R e_{\text {crit }}$ that was stated previously [12] for coiled tubes. In the literature, HCT setups cover a wide Dean number range from about 3 in the work of Klutz et al. [4] to 1049 in the work of Redlinger-Pohn et al. [13]. For a U-bend geometry [18], an increase in $D e$ from 50 to 1000 leads to a more uniform particle size distribution in the cross section with regard to size. Sandeep et al. confirmed the mixing with an increase in De for diffusion-free flow in the HCT [19]. For similar De as in our work, they observed that the mixing supports a narrow RT range. Klutz et al. explained that zero torsion $t$ leads to the narrowest RTD [4]. They reported that for the values of $t$ used in this work of below 0.001 there is no significant impact of torsion on the RTD.

Table 3. Dimensionless numbers to characterize the HCT geometry and the flow in the HCT. In the latter case, results are stated separately for the low and high mass flow rates $(0.0078$ and $0.0112 \mathrm{~kg} \mathrm{~s}^{-1}$ ). The dimensionless numbers were calculated for all three HCT sections, where the smallest and largest values are given.

\begin{tabular}{|l|l|l|l|l|}
\hline & \multicolumn{2}{|l|}{ Lower mass flow rate } & \multicolumn{2}{l|}{ Higher mass flow rate } \\
\hline & Min. & Max. & Min. & Max. \\
\hline$\lambda$ & 18 & 22 & 18 & 22 \\
\hline$P$ & 0.0231 & 0.0260 & 0.0231 & 0.0260 \\
\hline$R$ & 1490 & 1788 & 2125 & 2550 \\
$e$ & & & & \\
\hline$D$ & 335 & 381 & 477 & 544 \\
$e$ & & & & \\
\hline$t$ & $0.13 \times 10^{-4}$ & $0.17 \times 10^{-4}$ & $0.09 \times 10^{-4}$ & $0.12 \times 10^{-4}$ \\
\hline
\end{tabular}

In conductivity experiments, the time point of the conductivity increase equals the abovementioned average fluid RTs. As expected, the maximal value of the measured conductivity increased with pulse duration and mass flow for identical pulse duration. At $7.8 \mathrm{~g} \mathrm{~s}^{-1}\left(11.2 \mathrm{~g} \mathrm{~s}^{-}\right.$ $\left.{ }^{1}\right)$, an inlet pulse of $19 \pm 2 \mathrm{~s}$ (22 $\pm 2 \mathrm{~s}$ ) led to an increased outlet signal that was about 3.5 (2.3) times longer than the inlet signal at room temperature. Consequently, the conductivity pulse experiments showed that there was an intermediate amount of dispersion because of backmixing in the tube. As mentioned in Sect. 2, the backmixing is partially caused by the pressure pulsation of the pump.

For the dispersed phase, the experimental results are shown as the normalized number density distribution, $q_{0} / \max \left(q_{0}\right)$, in Fig. 3 for the lower mass flow of $7.8 \mathrm{~g} \mathrm{~s}^{-1}$ and the higher mass flow of $11.2 \mathrm{~g} \mathrm{~s}^{-1}$. The number density distribution was calculated with a bivariate Gaussian kernel density estimator [20] with a bandwidth matrix diagonal of $\left(10 \mathrm{~s}^{2}, 10 \mu \mathrm{m}^{2}\right)$. The crystal size range is similar for both mass flow rates, since growth was avoided in the experiments and the CSSD remained constant. 

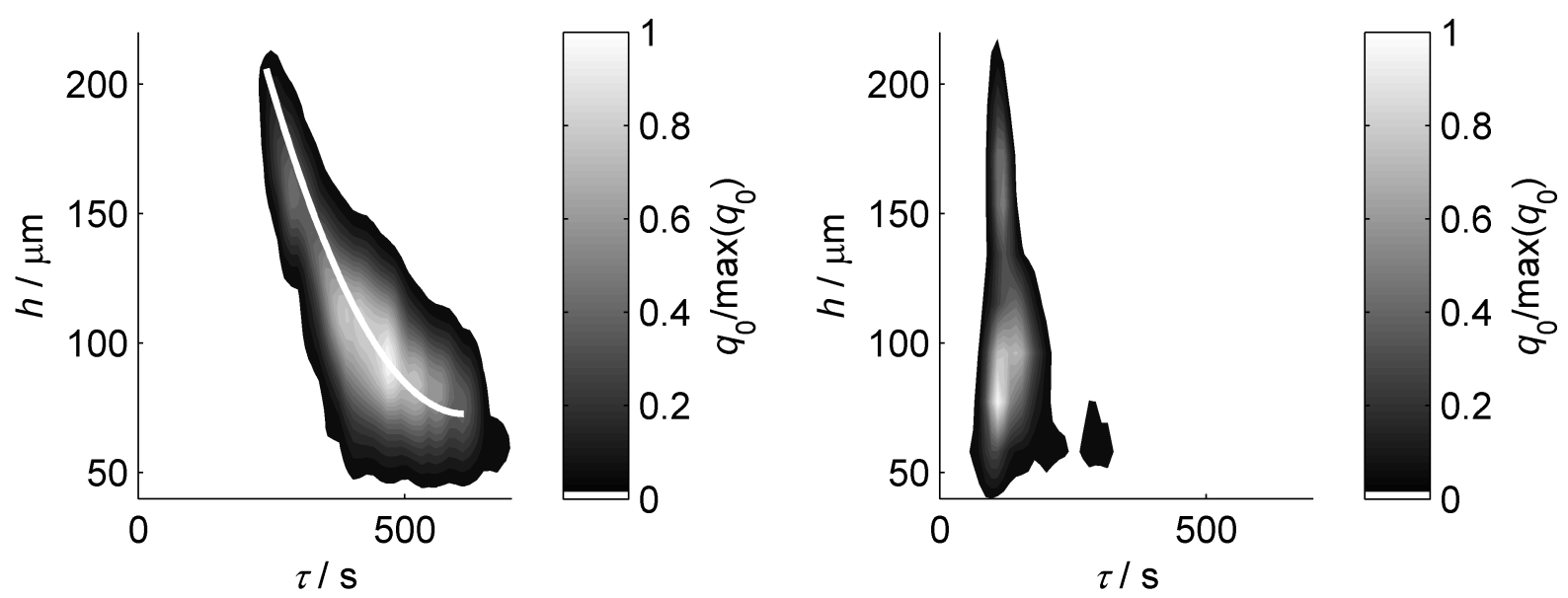

Figure 3. Normalized measured number density distributions under no-growth conditions: (a) $7.8 \mathrm{~g} \mathrm{~s}^{-1}$ with quadratic polynomial fit for the crystal residence time distribution $T(h)$; (b) $11.2 \mathrm{~g} \mathrm{~s}^{-1}$.

RTD data from nine separate experiments at a mass flow of $7.8 \mathrm{~g} \mathrm{~s}^{-1}$ were used to prepare Fig. 3 a. These experiments are listed in the upper part of Tab. 2. The RTD showed a quadratic dependency on the crystal size for the size range of the initial crystals. Therefore, small crystals remain in the tube longer and have more time to grow. This leads to a potential narrowing of the CSSD. Klutz et al. investigated continuous reactor concepts with narrow RTDs for all crystals at low $R e$ smaller than 100 and identified helically coiled setups, especially CFIs, as the systems that are closest to plug flow [4]. Although the HCT has a broader RTD, the separation effect can be applied for shape-selective crystallization if it is desired to make an initially broad CSSD narrower.

At a mass flow rate of $7.8 \mathrm{~g} \mathrm{~s}^{-1}$ and isothermal conditions, the largest crystal fraction of $155 \pm 27 \mu \mathrm{m}$ size exhibited a residence time $\tau$ of $275 \pm 30 \mathrm{~s}$, and the smallest crystal fraction of $89 \pm 36 \mu \mathrm{m}$ size had a $\tau$ of $460 \pm 84 \mathrm{~s}$. In Tab. 4, the crystal RT width is compared for the small, large, and mixed-fraction experiments given in Tab. 2. The mean $t$ of large crystals was considered over a size interval $h$ of 155 to $165 \mu \mathrm{m}$ for the separate large and mixedfraction experiments and over a size interval $h$ of 75 to $85 \mu \mathrm{m}$ for the separate small and mixed-fraction experiments. For both size ranges, the mean $t$ increased slightly by 24 to $25 \mathrm{~s}$ for the mixed case. The mean RT widths for the large and small fractions were constant. Furthermore, the RT is given at which a mass fraction $\omega$ of $10 \%$ of the large-crystal fraction and $90 \%$ of the small-crystal fraction had passed the HCT outlet. These values characterize the minimum and maximum $r$ at which crystals were observed in the mixed experiment and thus the width of the RTD. For octahedral crystals, the crystal mass can be calculated based on the size $h$. It is assumed that the difference in crystal velocity does not influence the 
number of observed crystals for the large and small fractions. Furthermore, an overlap of the fractions in RT is neglected, since $90 \%$ of the separate large fraction experiment had already left the HCT after $287 \mathrm{~s}$ while $10 \%$ of the small crystals reached the outlet with a considerable time difference after $367 \mathrm{~s}$. The RTs of the separate and mixed large fractions are similar. The RT of the slowest small crystals increased by about $30 \mathrm{~s}$ in the mixed experiment. This difference is similar to the mean value difference stated above. Consequently, the RTD was slightly broader in the mixed case. In conclusion, when both fractions were mixed before seeding, similar RTDs were observed with a similar CSSD.

Table 4. Mean residence time of crystals $\tau$ in separate and mixed-fraction experiments for a mass flow of $7.8 \mathrm{~g} \mathrm{~s}^{-1}$. In the mixed experiments, the mass fraction $\omega$ was calculated for the small and large fractions on the basis of the seed mass in Tab. 2. In the case of the small and mixed-fraction experiments, the mean of the mean $\tau$ is given for two experiments.

\begin{tabular}{|l|l|l|l|l|}
\hline & $\omega$ of $10 \mathrm{wt} \%$ & $h$ of 155 to $165 \mu \mathrm{m}$ & $h$ of 75 to $85 \mu \mathrm{m}$ & $\begin{array}{l}\omega \text { of } \\
90 \text { wt } \\
\%\end{array}$ \\
\hline & Mean $\tau[\mathrm{s}]$ & \multicolumn{3}{l|}{} \\
\hline Large fraction & 252 & 276 & - & 287 \\
\hline Large fraction in mix & 244 & 300 & - & 318 \\
\hline Small fraction & 367 & - & 485 & 561 \\
\hline Small fraction in mix & 339 & - & 510 & 591 \\
\hline
\end{tabular}

Fig. $3 \mathrm{~b}$ shows the crystal RTDs at the higher mass flow of $11.2 \mathrm{~g} \mathrm{~s}^{-1}$ (averaged data from six experiments). The sieve sizes for these experiments are listed in Tab. 2. As expected, shorter RTs were observed for $11.2 \mathrm{~g} \mathrm{~s}^{-1}$. The largest crystal fraction of $159 \pm 85 \mu \mathrm{m}$ size had a $\tau$ of $116 \pm 26 \mathrm{~s}$, whereas the smallest crystal fraction of $89 \pm 58 \mu \mathrm{m}$ size had a mean $\tau$ of $160 \pm 84$ $\mathrm{s}$ (median: $139 \mathrm{~s}$ ). At $11.2 \mathrm{~g} \mathrm{~s}^{-1}$, the first small crystals had a RT that was similar to the RT of the continuous phase, whereas there was a large slip between the average velocities of the continuous and the dispersed phases for $7.8 \mathrm{~g} \mathrm{~s}^{-1}$. The HCT is now characterized in terms of the RT behavior. Overall, there is considerable dispersion and a size-dependent crystal RT at laminar fluid velocity. The mixing of different size fractions does not significantly influence the $\mathrm{RT}$ in the considered size range. The size-dependent RT may be caused by the complex flow profile in the HCT. Furthermore, crystal-crystal and crystal-wall collisions may lead to this effect depending on the suspension density.

In the following, the RTD is discussed in relation to density, particle size, and fluid velocity in comparison to the literature for different tubes and channels. Segre and Silberberg reported that neutrally buoyant particles collect in a thin annular region during laminar flow through a straight tube [21]. This pinch effect was dependent on the tube length, mean fluid velocity, 
and the ratio of particle to tube radius. The particle to internal tube diameter ratio was larger compared to this work and the fluid and particle densities were identical. The SegreSilberberg effect can potentially lead to a distributed RT because of the arrangement of the particles in a line. Later, the Segre-Silberberg effect was observed by Di Carlo et al. in a rectangular cross-section microchannel [22]. In their work, the particle velocities were largely independent of particle size and only the rotational velocity was affected by size.

Sandeep et al. [19] and Cheng et al. [23] analyzed the RT of spherical particles in a HCT. In their setup, the particle density was equal to the fluid density. The particle to internal tube diameter ratio and the mean fluid velocity were slightly larger than in this work. In general, they observed that a decrease in axial fluid velocity led to an increase in mean, minimum, and maximum RT and standard deviation. The same results can be observed in this work by comparing Fig. 3 a and Fig. 3 b. Sandeep et al. found that an increase in particle size resulted in a slight decrease in mean RT and a significant decrease in the minimum and standard deviation of the RT [19]. The decreases in mean RT and the decrease in standard deviation agree with the results in this work (see Fig. 3). Cheng et al. stated that the computational results did not indicate the existence of the Segre-Silberberg effect in Poiseuille flow in a helical pipe [23].

Compared to the literature reports mentioned previously, the particle density was higher than the fluid density in our work and in the simulations of Tiwari et al. [18] for a HCT. Following Tiwari et al., the particle-settling zone is at the inner bend of the horizontal helical tube. The shift from the bottom to the inner bend of the tube is explained by the gravitational force and the direction of the shear force by secondary flow. The secondary flow also helps in distributing particles in the cross section. This effect is enhanced for small particles [18], which may lead to differences in RT.

In agreement with the simulations of Tiwari et al. [18], Redlinger-Pohn et al. found in experiments that small fibers were well mixed in a HCT and had large RTs compared to long fibers [13]. The separation was less pronounced in their simulations [13]. On the one hand, they ascribed the difference in RT to flocculation. On the other hand, they explained the separation according to size by the ratio of the sedimentation speed of the fibers and the secondary motion of the fluid. The second argument is also suitable to explain the sizedependent separation for single crystals in this work. In order to improve the understanding of the flow-particle interactions, we have previously investigated this phenomenon for a simplified geometry in more detail [24]. 
Overall, in agreement with the literature, it was found that the mean particle RT decreased with increasing fluid velocity and increasing particle size. Furthermore, it is in line with literature observations that an increase in the standard deviation and thus the distribution width accompanies decreases in fluid velocity and particle size. These effects have not yet been noted experimentally for compact single crystals in HCTs. The secondary flow in HCTs is of importance in explaining the particle motion as stated by Redlinger-Pohn et al. [13] and Tiwari et al. [18].

In RTD experiments, it was observed that the crystal RT was size dependent and that the crystal velocity was larger than the mean fluid velocity. In the following, potential consequences for growth experiments are discussed. The RT of the small crystals is larger than the RT of the large crystals. Consequently, the small crystals have more time to grow. During growth, the potash alum concentration in the solution is reduced. When the fluid is faster than the crystals and pulsed seeding is used at the inlet, the slowest crystals are fed with solution of the original inlet concentration. Hence, the slow small crystals are exposed to a higher supersaturation and reach higher growth rates than the fast large crystals. The supersaturation differences are expected to be small because of low suspension densities. Overall, the increased RT and higher supersaturation for small crystals lead to a potential narrowing of the CSSD, whereas growth rate dispersion is expected to broaden the CSSD.

Crystal growth was realized without blocking for seeded crystallization. Fig. 4 shows the density distribution of the smallest crystal fraction at the HCT outlet after growth for three experiments at $7.8 \mathrm{~g} \mathrm{~s}^{-1}$. From Fig. 4 a to Fig. $4 \mathrm{c}$, the supersaturation ratio [11] at the HCT outlet increases. A similar saturation temperature of the solution was applied in all experiments. The median size increased $(98,133$, and $141 \mu \mathrm{m})$ while the median RT decreased $(392,388$, and $324 \mathrm{~s})$. The decrease of the median RT is in agreement with the RT under no-growth conditions, since the growing crystals became larger and thus faster. The growth rates were estimated assuming a constant concentration in the continuous phase because of low suspension densities and for an initial median size of $85 \mu \mathrm{m}$. The estimated growth rates between 0.03 and $0.18 \mu \mathrm{m} \mathrm{s}^{-1}$ for an absolute supersaturation of 1.02 to 1.19 (see Fig. 4) are comparable with the results of Mullin [11] and in the range of literature values reported by Ma et al. [25]. Small crystals were observed in the experiment with the highest supersaturation ratio. The addition of crystals may have induced nucleation at different positions in the HCT and therefore the concept of RT may not be applicable for these nucleated crystals. 

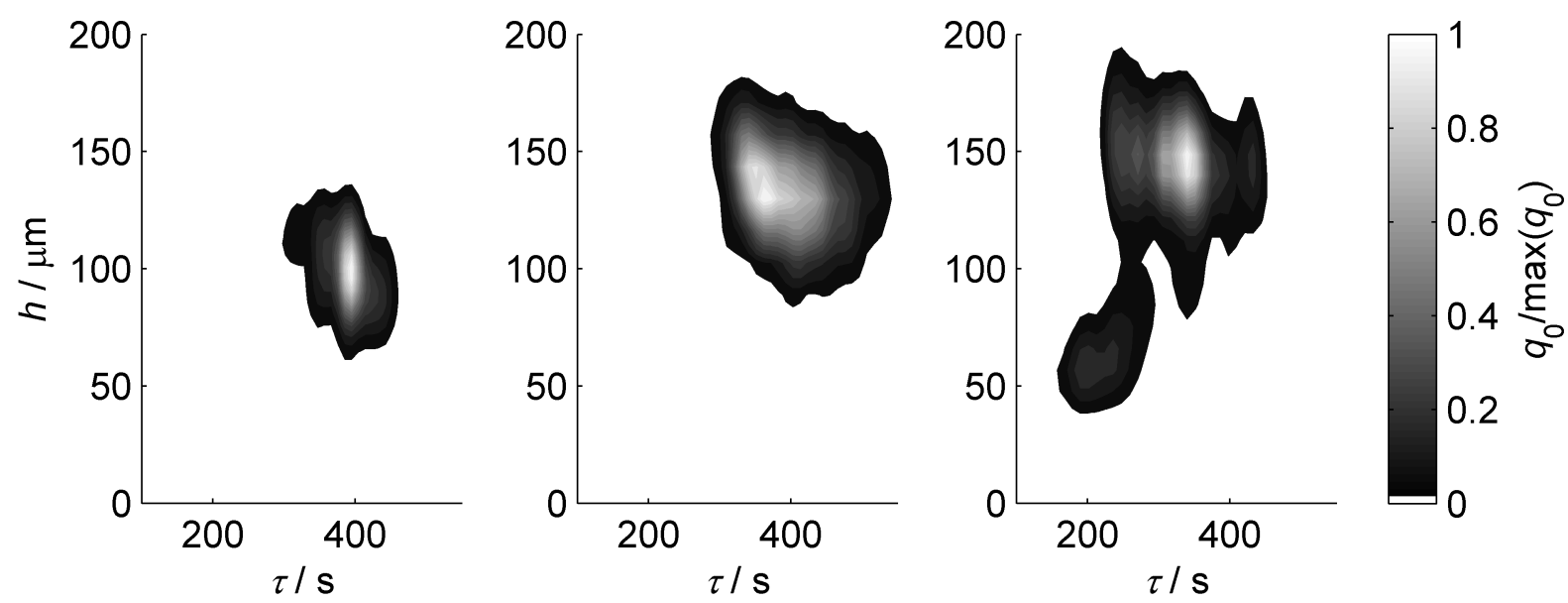

Figure 4. Normalized measured number density distributions at the helically coiled flow tube outlet for increasing outlet supersaturation ratios: (a) 1.02, (b) 1.14, and (c) 1.19 at a saturation temperature of $313 \mathrm{~K}$ for the smallest crystal size fraction.

\section{Conclusions}

Univariate potash alum crystals can grow successfully in the HCT setup without tube blocking. A separation effect by crystal size was identified for the laminar average fluid velocity. Small crystals have higher residence times and more time for crystal growth. Thus, the HCT has the potential to narrow the CSSD during growth. The univariate shapes of the crystal projections at the HCT outlet were successfully estimated for the applied low suspension densities. In future research, shape-specific growth rates will be analogously determined for bivariate substances, e.g., potassium dihydrogen phosphate, or multivariate substances, and these will be compared to existing batch experiments, e.g., those concerning a bivariate substance reported by Eisenschmidt et al. [26].

\section{Acknowledgement}

The financial support of the Deutsche Forschungsgemeinschaft (DFG) within the priority program SPP 1679 "Dynamic flowsheet simulation of interconnected solids processes" under the grant number SU 189/6-2 is gratefully acknowledged.

\section{Symbols used}

Symbols:

$\begin{array}{lll}d & {[\mathrm{~m}]} & \text { internal tube diameter } \\ \text { De } & {[-]} & \text { Dean number } \\ h & {[\mu \mathrm{m}]} & \text { perpendicular distance of the crystal center to the crystal faces } \\ l & {[\mathrm{~m}]} & \text { tube arc length at the centerline of the tube } \\ p & {[\mathrm{~m}]} & \text { screw pitch as distance between the centers of two stacked coils }\end{array}$




$\begin{array}{lll}P & {[-]} & \text { dimensionless pitch } \\ q_{0} & {\left[\# \mu \mathrm{m}^{-1} \mathrm{~s}^{-1}\right]} & \text { number density distribution } \\ r & {[\mathrm{~m}]} & \text { internal tube radius } \\ r_{\mathrm{c}} & {[\mathrm{m}]} & \text { coil radius } \\ \operatorname{Re} & {[-]} & \text { Reynolds number } \\ R e_{\text {crit }} & {[-]} & \text { critical Reynolds number } \\ t & {[-]} & \text { torsion parameter } \\ v & {\left[\mathrm{~m} \mathrm{~s}^{-1}\right]} & \text { average fluid velocity } \\ w & {\left[\mathrm{~m}^{2}\right.} & \text { tube wall thickness }\end{array}$

Greek symbols:

$\begin{array}{lll}\lambda & {[-]} & \text { curvature ratio } \\ \mu & {\left[\mathrm{kg} \mathrm{m}^{-1} \mathrm{~s}^{-1}\right]} & \text { dynamic viscosity of the fluid } \\ \rho & {\left[\mathrm{kg} \mathrm{m}^{3}\right]} & \text { fluid density } \\ T & {[\mathrm{~s}]} & \text { crystal residence time } \\ \omega & {[-]} & \text { mass fraction at the HCT outlet }\end{array}$

Sub- and Superscripts:

$i \quad$ tube section index

Abbreviations:

CFI

coiled flow inverter

CSSD crystal size and shape distribution

HCT helically coiled flow tube

RT residence time

RTD residence time distribution

\section{References}

[1] C. Borchert, K. Sundmacher, Chem. Eng. Technol. 2011, 34 (4), 545-556. DOI: 10.1002/ceat.201000465

[2] S. Vashisth, K. D. P. Nigam, Chem. Eng. Process. 2009, 48 (1), 452-463. DOI: 10.1016/j.cep.2008.06.006

[3] L. Hohmann, R. Gorny, O. Klaas, J. Ahlert, K. Wohlgemuth, N. Kockmann, Chem. Eng. Technol. 2016, 39 (7), 1268-1280. DOI: 10.1002/ceat.201600072

[4] S. Klutz, S. K. Kurt, M. Lobedann, N. Kockmann, Chem. Eng. Res. Des. 2015, 95, 22-33. DOI: 10.1016/j.cherd.2015.01.003 
[5] R. J. P. Eder, S. Radl, E. Schmitt, S. Innerhofer, M. Maier, H. Gruber-Woelfler, J. G. Khinast, Cryst. Growth Des. 2010, 10 (5), 2247-2257. DOI: 10.1021/cg9015788

[6] R. J. P. Eder, S. Schrank, M. O. Besenhard, E. Roblegg, H. Gruber-Woelfler, J. G. Khinast, Cryst. Growth Des. 2012, 12 (10), 4733-4738. DOI: 10.1021/cg201567y

[7] M. O. Besenhard, A. Thurnberger, R. Hohl, E. Faulhammer, J. Rattenberger, J. G. Khinast, Int. J. Pharm. 2014, 475 (1-2), 198-207. DOI: 10.1016/j.ijpharm.2014.08.009

[8] M. O. Besenhard, P. Neugebauer, C.-D. Ho, J. G. Khinast, Cryst. Growth Des. 2015, 15 (4), 1683-1691. DOI: 10.1021/cg501637m

[9] S. Schorsch, J.-H. Hours, T. Vetter, M. Mazzotti, C. N. Jones, Comput. Chem. Eng. 2015, 75, 171-183. DOI: 10.1016/j.compchemeng.2015.01.016

[10] C. Borchert, E. Temmel, H. Eisenschmidt, H. Lorenz, A. Seidel-Morgenstern, K. Sundmacher, Cryst. Growth Des. 2014, 14 (3), 952-971. DOI: 10.1021/cg401098x

[11] J. W. Mullin, Crystallization, 4th ed., Butterworth-Heinemann, Oxford 2001.

[12] S. Vashisth, V. Kumar, K. D. P. Nigam, Ind. Eng. Chem. Res. 2008, 47 (10), 32913337. DOI: $10.1021 / \mathrm{ie} 701760 \mathrm{~h}$

[13] J. D. Redlinger-Pohn, L. A. Jagiello, W. Bauer, S. Radl, Int. J. Multiphase Flow 2016, 83, 239-253. DOI: 10.1016/j.ijmultiphaseflow.2016.04.008

[14] N. Kubota, K. Shimizu, H. Itagaki, J. Cryst. Growth 1985, 73 (2), 359-363. DOI: 10.1016/0022-0248(85)90313-6

[15] J. W. Mullin, J. Garside, R. Unahabhokha, J. Appl. Chem. 1965, 15 (11), 502-505. DOI: $10.1002 /$ jctb.5010151103

[16] M. Sommerfeld, in VDI-Wärmeatlas, 11th ed. (Ed: VDI e.V.), Springer, Berlin 2013, Ch. L3.1.

[17] V. Kubair, C. B. S. Varrier, Trans. Indian Inst. Chem. Eng. 1961/62, 14, 93-97.

[18] P. Tiwari, S. P. Antal, M. Z. Podowski, Phys. Fluids 2006, 18 (4), 043304. DOI: $10.1063 / 1.2189212$

[19] K. P. Sandeep, C. A. Zuritz, V. M. Puri, J. Food Sci. 1997, 62 (4), 647-652. DOI: 10.1111/j.1365-2621.1997.tb15428.x

[20] Y. Ciao, Bivariant Kernel Density Estimation (V2.1), MATLAB Central File Exchange, https://de.mathworks.com/matlabcentral/fileexchange/19280-bivariant-kernel-densityestimation--v2-1-, accessed 15 Nov 2015.

[21] G. Segre, A. Silberberg, Nature 1961, 189 (4760), 209-210. DOI: 10.1038/189209a0

[22] D. Di Carlo, J. F. Edd, K. J. Humphry, H. A. Stone, M. Toner, Phys. Rev. Lett. 2009, 102 (9), 094503. DOI: 10.1103/PhysRevLett.102.094503

[23] L. Cheng, A. V. Kuznetsov, K. P. Sandeep, Int. J. Numer. Methods Fluids 2005, 48 (6), 649-670. DOI: 10.1002/fld.950

[24] V. Wiedmeyer, F. Anker, C. Bartsch, A. Voigt, V. John, K. Sundmacher, Ind. Eng. Chem. Res. 2017, 56 (13), 3699-3712. DOI: 10.1021/acs.iecr.6b04279 
[25] C. Y. Ma, J. Wan, X. Z. Wang, Powder Technol. 2012, 227, 96-103. DOI: 10.1016/j.powtec.2012.02.040

[26] H. Eisenschmidt, A. Voigt, K. Sundmacher, Cryst. Growth Des. 2015, 15 (1), 219-227. DOI: $10.1021 / \operatorname{cg} 501251 \mathrm{e}$

\section{Short text for the table of contents section}

The shape of a crystal strongly affects its properties. A helically coiled tube crystallizer was investigated for shape-selective crystal growth, using a flow-through microscope to analyze the crystal size and shape distribution for potash alum. Residence time distribution measurements showed separation according to particle size. Larger crystals were found to travel faster than small crystals. 